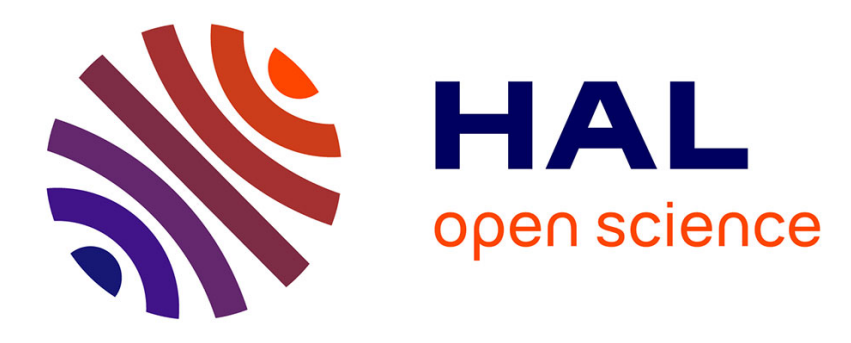

\title{
Effects of alcohol on automated and controlled driving performances
}

Catherine Berthelon, Guy Gineyt

\section{To cite this version:}

Catherine Berthelon, Guy Gineyt. Effects of alcohol on automated and controlled driving performances. Psychopharmacology, 2014, 231 (10), pp. 2087-2095. 10.1007/s00213-013-3352-x . hal00984949

\section{HAL Id: hal-00984949 \\ https://hal.science/hal-00984949}

Submitted on 29 Apr 2014

HAL is a multi-disciplinary open access archive for the deposit and dissemination of scientific research documents, whether they are published or not. The documents may come from teaching and research institutions in France or abroad, or from public or private research centers.
L'archive ouverte pluridisciplinaire HAL, est destinée au dépôt et à la diffusion de documents scientifiques de niveau recherche, publiés ou non, émanant des établissements d'enseignement et de recherche français ou étrangers, des laboratoires publics ou privés. 
Psychopharmacology, Vol. 231 (10), pp 2087-2095

Springer - DOI: 10.1007/s00213-013-3352-x

http://link.springer.com/article/10.1007/s00213-013-3352-x

Effects of alcohol on automated and controlled driving performances

Catherine Berthelon ${ }^{1}$, Guy Gineyt ${ }^{2}$

${ }^{1}$ IFSTTAR (The French Institute of Science and Technology for Transport, Development and Networks), LMA (Laboratory of Accident Mechanism Analysis), Chemin de la CroixBlanche, 13300 Salon de Provence, France

IFSTTAR, LMA, F-13300, Salon de Provence, France

${ }^{2}$ Hospital Center, Department of Medical Information, 207 Avenue Julien Fabre, 13300 Salon de Provence, France

Corresponding author

Catherine Berthelon

IFSTTAR-LMA

Chemin de la Croix-Blanche

13300 Salon de Provence

France

Mail: catherine.berthelon@ifsttar.fr

Telephone: +33490568612

Fax: +33490568618 


\begin{abstract}
Rationale: Alcohol is the most frequently detected substance in fatal automobile crashes, but its precise mode of action is not always clear.

Objective: The present study was designed to establish the influence of blood alcohol concentration as a function of the complexity of the scenarios. Road scenarios implying automatic or controlled driving performances were manipulated in order to identify which behavioral parameters were deteriorated.
\end{abstract}

Method: A single blind counterbalanced experiment was conducted on a driving simulator. Sixteen experienced drivers $(25.3 \pm 2.9$ years old, 8 men and 8 women $)$ were tested with 0 , $0.3 \mathrm{~g} / \mathrm{l}, 0.5 \mathrm{~g} / \mathrm{l}$ and $0.8 \mathrm{~g} / \mathrm{l}$ of alcohol. Driving scenarios varied: road tracking, car following and an urban scenario including events inspired by real accidents. Statistical analyses were performed on driving parameters as a function of alcohol level.

Results: Automated driving parameters such as standard deviation of lateral position (SDLP) measured with the road tracking and car following scenarios were impaired by alcohol, notably with the highest dose. More controlled parameters such as response time to braking and number of crashes when confronted with specific events (urban scenario) were less affected by the alcohol level.

Conclusion: Performance decrement was greater with driving scenarios involving automated processes than with scenarios involving controlled processes.

\title{
Key words
}

Alcohol, scenarios, driving, simulator, performance 


\section{Introduction}

Consumption of psychoactive drugs produces a decrease in the mental and behavioral functions involved in automobile driving (Moskowitz and Fiorentino 2000; Odgen and Moskowitz 2004). In particular, it has been shown for many years that impairment of driving due to ethanol is a main factor in road traffic accidents and that blood alcohol concentration (BAC) is clearly linked with the probability of being involved in a road accident (Borkenstein et al. 1964; Robertson and Drummer 1994; Zador et al. 2000; Blomberg et al. 2009; Phillips and Brewer 2011). Alcohol is thus the most commonly detected substance in fatally injured drivers, and epidemiological evidence indicates that the risk of accident increases with alcohol alone and when alcohol is combined with licit or illicit psychotropic drugs (Skurtveit et al. 2002; Odgen and Moskowitz 2004; Vingilis and MacDonald 2004; Walsh et al. 2004; Brady and Li 2012; Mørland et al. 2011). The relative risk estimated using the Odds Ratio is of 5.6 for a BAC between 0.5 and $0.79 \mathrm{~g} / 1$ and of 15.5 for alcoholization greater than or equal to 0.8 g/l (Movig et al. 2004); the number of drivers responsible for accidents rises to 2.3 for cannabis alone, to 9.4 for alcohol alone, and to 14.1 for the alcohol-cannabis combination (Biecheler et al. 2008).

The precise mode(s) of alcohol's action are not always clear; it does not uniformly impair all aspects of performance, but most experimental studies show a global behavioral decrement from $0.5 \mathrm{~g} / \mathrm{l}$ of alcohol in the blood (Moskowitz and Firentino 2000). In case of multiple tasks, people under the influence of alcohol tend to favor just one task, resulting in a strong decrease in performance for the secondary task from $0.2 \mathrm{~g} / \mathrm{l}$; some cognitive capacities (memory, response time) are affected from near $0.5 \mathrm{~g} / 1$ (Parks et al. 2002) and can show a dose effect (Bisby et al. 2009). Vigilance level and eye tracking are also affected at very low doses of alcohol (Moskowitz et al. 1985) and motor functions appear to be more affected than cognitive functions (Koelega 1995). Concerning driving, studies on simulators and on the 
road show deterioration in behavior starting at low level of alcohol; this deterioration increases with task difficulty (Ogden and Moskowitz 2004; Lenné et al. 2010). Decisionmaking processes appear to be less affected than drivers' ability to divide attention, and the impairing effects of alcohol on performances is thus intensified when the driver is required to divide attention among distractor tasks while driving (Leung and Starmer 2005; Verster et al. 2009; Harrison and Fillmore 2011). Moreover, some alcohol effects on driving performances and risky driving are more pronounced in the presence of a response conflict, for example by increasing deviations in lane positions and failures to stop at red lights (Fillmore et al. 2008). Alcohol has thus consistently been found to produce dose-dependent impairment in the performance of driving tasks and of driving relative cognitive tasks (Ronen et al. 2010; Leung et al. 2012).

One of the most often used scenarios to evaluate driving behavior after the ingestion of psychotropic drugs was initiated in pharmacology procedures with antihistaminic drugs and benzodiazepine (O'Hanlon and Volkerts 1986; Ramaekers and O'Hanlon 1994). The highway driving test consists in registering driver's action parameters in monotonous driving scenarios such as motorway situations, causing a clear deterioration of different driving parameters. In particular, the primary outcome measured is the standard deviation of lateral position (SDLP) of the driver's vehicle. This behavioral variable reflects the capacity (or the inaptitude) to keep the vehicle from swaying from side to side, so it is a good indicator of vehicle control and increases in case of less control. SDLP is extremely sensitive to modifications involving psychotropic drugs and fatigue. It is frequently used to quantify the negative effects of these factors in natural or simulated driving (O'Hanlon et al. 1982, Brookhuis 1998; Arnedt et al. 2001; Brookhuis et al. 2003; Vermeeren 2004; Philip et al. 2005; Verster and Ramaekers 2009; Verster and Roth 2012a, Helland et al. 2013). The highway driving test also shows a dose-dependent relationship between the alcohol dose and performance degradation 
(Louwerens et al. 1987). Automated driving performance, as measured by this test, is impaired by alcohol $(0.4 \mathrm{~g} / \mathrm{l})$ and SDLP increases, while speed (SD) and the standard deviation of speed (SDSP) are sometimes increased (Arneth et al. 2001, Lenné et al., 2010; Ronen et al., 2010) and sometimes unaffected (West et al. 1993; Kuypers et al. 2006). However, the monotonous scenarios used to obtain SDLP effectively measure lower level behavior functions but not higher level functions such as response to emergency situations and risk-taking behavior, although, for example, the detection of danger can be slower with alcohol (West et al. 1993). It is only more recently that research has systematically turned to behavioral modifications involving psychotropic drugs in more stimulating scenarios rather than monotonous ones, e.g. scenarios reflecting controlled modes of cognitive processing, such as car following scenarios and complex urban scenarios requiring set-shifts and cognitive strategies (Leung and Starmer 2005; Lenné et al. 2010; Simons et al. 2012). According to Michon's three-level driving model (1985), automated driving behavior concerns immediate parameters like lateral and longitudinal control of the vehicle (e.g. speed and lateral position in the lane), while controlled driving behavior concerns driving actions such as maneuvers when faced with specific events. Recent results tend to show that under the influence of alcohol, automated driving performances such as speed and SDLP measured in monotonous situations are mainly influenced. Driving parameters such as response time or gap acceptance when crossing an intersection, which are involved in more complex situations such as car following and urban driving performances, are not affected, however (Veldstra et al. 2012). Thus, lane keeping performances deteriorate to some extent but drivers are still able to adequately react to road signs indicating a lane change (Huemer and Vollrath 2010). These results are not in line with others which postulate that controlled performances and simulator tasks would be degraded earlier with low doses of alcohol in the blood while automated 
performances would only be so later, e.g. that automated processes are less sensitive to alcohol-induced impairment (Fisk and Schneider 1982; Krüger 1993; Holloway 1995).

Based on the aforementioned alcohol results, we decided to test the effects of different BACs on automated and more controlled driving performances to establish their respective influences on behavioral decrement. Automated and controlled driving parameters were analyzed with various driving scenarios. The BAC limits used were the BAC levels at which the accident risk is increased as well as the BAC limits generally tolerated in European countries. The BAC levels of $0.5 \mathrm{~g} / 1$ and $0.8 \mathrm{~g} / 1$ were thus selected to remain consistent with the legal limits in most European countries, the $0.3 \mathrm{~g} / 1$ level was selected relative to other countries which have already adopted a lower limit and in agreement with a consortium of researchers involved in the DRUID project ${ }^{1}$ such as Veldstra et al. (2012). In the present research, it was predicted that performances would deteriorate with increasing blood alcohol concentrations and, in comparison with the results of driving studies, would be more affected for scenarios implying automated driving performances than for scenarios implying more controlled driving performances.

\section{Method}

\subsection{Design}

The study was conducted according to a balanced, single-blind, cross-over design. Each participant followed four experimental sessions balanced for order with a Williams's square design (Williams, 1949). Experimental sessions began at $1 \mathrm{pm}$. Each session was separated from the following by a washout period of at least 2 days.

Before each session, participants drank a beverage (vodka $40 \%$ and/or orange juice) in order to obtain a BAC of 0 (placebo), $0.3,0.5$ or $0.8 \mathrm{~g} / 1$.

\footnotetext{
${ }^{1}$ In the DRUID project, the objective was to dispose of baseline impairments due to different levels of alcohol for comparison with impairments due to other licit and illicit drugs.
} 
Doses of ethanol were calculated for each volunteer using the following formulae (Tiplady et al., 2005):

$[3.82-(0.143 \times \mathrm{A})+(0.168 \times \mathrm{H})+(0.525 \times \mathrm{W})] \times \mathrm{T} / 100$ for males

$[-3.67+(0.187 \times \mathrm{H})+(0.432 \times \mathrm{W})] \times \mathrm{T} / 100$ for females

Where $\mathrm{A}$ is age (years); $\mathrm{H}$ is height $(\mathrm{cm})$; $\mathrm{W}$ is weight $(\mathrm{kg})$; and $\mathrm{T}$ is the target concentration $(\mathrm{mg} / 100 \mathrm{ml})$.

Duration of drinking was around 15 minutes $(\mathrm{mn})$. Time between the end of alcohol intake and driving was around $20 \mathrm{mn}$ and was preceded by a verification of the BAC. The alcohol level was measured using a breathalyzer (SD-400 DJP/LION).

\subsection{Participants}

Sixteen drivers ( 8 men and 8 women) aged from 21 to 29 years $(\mathrm{m}=25.31, \mathrm{SD}=2.87)$ and with a minimum of two years of driving experience were included in this experiment. Before inclusion, participants had a medical check-up and it was verified that they had no prior problems with drug or alcohol abuse. First-time consumers of alcohol and excessive drinkers were not accepted. Participants were instructed to abstain from alcohol the day before the experimental session, to avoid caffeinated beverages and to eat just a light meal before each experimental session. For each session, participants were transported from home to the laboratory by IFSTTAR staff.

All participants gave written informed consent and signed informed commitment prior to inclusion in the study. They were compensated for their participation.

The study was granted ethical approval by the French local ethics committee and by the French Health Products Safety Agency.

\subsection{Apparatus}

The driving experiment was carried out on the SIM2-IFSTTAR fixed-base driving simulator. The simulator consisted of a one-quarter vehicle and 3 video projectors. The drivers' visual 
environment was generated using the ARCHISIM (2011 release) software package (Espié and Auberlet, 2007). The vehicle had an automatic gearbox and was not equipped with rear view mirrors. The image projection surface underlay an angular opening that spanned $150^{\circ}$ horizontally and $40^{\circ}$ vertically (Fig. 1). Images were refreshed at the rate of $30 \mathrm{~Hz}$. Drivers controlled the vehicle using the steering wheel, the brake and accelerator pedals. The acquisition frequency for the different signals (position, speed, acceleration, etc.) was around $30 \mathrm{~Hz}$.

\subsection{Driving scenarios}

During each experimental session $(0,0.3,0.5$ or $0.8 \mathrm{~g} / \mathrm{l})$, participants were presented with three driving scenarios. The order of presentation of the three scenarios was randomized within each session, and the BAC level was measured before each of them. To avoid any learning effect during the experimental sessions, participants were extensively trained on the different scenarios the day of the medical examination.

\subsubsection{Highway scenario $(15 \mathrm{mn})$}

The participants drove on a highway, without any traffic. They were instructed to drive with a steady position within the right traffic lane while maintaining a constant speed of $110 \mathrm{~km} / \mathrm{h}$ during the test. "They were free to choose their preferred position within the traffic lane" as in Verster and Roth (2011), so they could drive as in their usual, natural position. The duration of this task is longer (more than twice as long) than in Veldstra et al. (2012). Moreover, at the end of the circuit, they were confronted with a vehicle stopped in their lane with a time to collision of $2.5 \mathrm{~s}$. The mean lateral position of the vehicle from the centre of the right lane (LP), standard deviation of lateral position (SDLP), mean speed (SD) and standard deviation of speed (SDSD) were calculated across all data points during one drive (excluding values obtained with a radius of curvature of less than $1000 \mathrm{~m}$ ). The number of off-lane incidents was also calculated (number of times that the participant left the right lane). The number of 
collisions and response times (RT) by the participants when confronted with a stopped vehicle at the end of the test were also noted. RT corresponded to the time difference between the apparition of the obstacle vehicle and the first press on the brake pedal.

\subsubsection{Car following scenario $(10 \mathrm{mn})$}

The participants had to follow a lead car at a short distance, but one considered to be safe. Their task was to keep this distance constant whereas the lead car was programmed to randomly accelerate or decelerate. The speed of the lead vehicle could vary from 70 to 90 $\mathrm{km} / \mathrm{h}( \pm 10$ or $20 \mathrm{~km} / \mathrm{h}$ ) but the vehicle did not continuously accelerate and decelerate as in the study by Veldstra et al. (2012). Each speed change was separated from another by a period of stable speed. The duration of stable speed was 20,30 or $40 \mathrm{~s}$.

Mean SDLP, Inter Vehicular Time (IVT, distance from the rear of the leading vehicle to the front of the following vehicle/participant's speed), the number of adjustments of speed during stable speed of lead vehicle, e.g. the number of times the participant's speed was lower or higher than the lead vehicle's speed, and response time delay after the lead vehicle's speed modification were analyzed. Analysis of speed and speed deviation were not relevant as linked to the speed of the lead vehicle.

\subsubsection{Urban scenario (10 mn)}

The participants drove along a realistic urban circuit where a few independent vehicles with non-conflicting behavior were also driving. The participants' task consisted in driving at 50 $\mathrm{km} / \mathrm{h}$, as usual. Seven prototypical events, inspired by real accidents, were also included in a counterbalanced order in the circuit. These events were spatio-temporally implemented using data from the Detailed Accident Study collected by the Laboratory of Accident Mechanism Analysis (LMA) at IFSTTAR (Perrin et al. 2004). As our objective was to include difficult situations on the simulator and not situations that systematically produced accidents, we 
adapted the different values from the accident reconstitution so that drivers on the simulator could develop collision avoidance strategies (Berthelon et al. 2011; Damm et al. 2011).

In Veldstra et al. (2012), only three urban events were used. They were not really constructed with spatio-temporal reconstitutions of real accidents. One event assessed risk-taking in traffic (the time interval accepted by participants to turn left as oncoming traffic arrived), another tested violations of traffic regulations using a traffic light scenario, and the last one was, as in the present study, a vehicle pulling out of a parking space. The events used here tested the participants' maneuvers and their efficiency. Three events ( $a, b$ and $c)$ were unexpected and four could be foreseen ( $\mathrm{d}, \mathrm{e}, \mathrm{f}$ and $\mathrm{g})$ :

a) Hidden pedestrian crossing. A pedestrian, initially hidden by a bus parked on the right-hand side of the carriageway, suddenly crosses the carriageway. The pedestrian appears in the driver's field of vision 2.4 seconds before the driver reaches his level.

b) Right crossroads. The driver arrives at an intersection without visibility. A vehicle comes from the right at $8 \mathrm{~km} / \mathrm{h}$, and can be seen from only 25 meters.

c) Vehicle pulling out from a parking space. A vehicle parked on the right-hand side of the carriageway pulls out of its parking space when the driver is at a distance of $20 \mathrm{~m}$.

d) Vehicle overtaking and merging back into the lane. A vehicle overtakes the participant's vehicle, then merges back ahead of him and slows down to a speed of 30 $\mathrm{km} / \mathrm{h}$.

e) Left crossroads. A vehicle coming from the left of an intersection starts to slow down for $4 \mathrm{~s}$, adopting a speed of $5 \mathrm{~km} / \mathrm{h}$ when reaching the crossroads.

f) Braking by the vehicle ahead. The driver follows a lead vehicle whose speed depends on his/her own speed, so that the distance between the two vehicles is $25 \mathrm{~m}$. Suddenly, the coupling is broken and the obstacle vehicle slows down to a speed of $10 \mathrm{~km} / \mathrm{h}$. 
g) Opposite vehicle crossing. A vehicle in front of the driver gets ready to turn left into a petrol station and starts to cross the opposite lane, when the subject's vehicle is at a distance of $25 \mathrm{~m}$ from the potential point of impact.

In case of crashes, the vehicle being driven passes through the vehicle with which it crashes and the participant can continue the circuit without interruption.

The number of collisions, SD at the origin of the urban events (for example, at the initiation of braking of the obstacle vehicle) and RT were analyzed.

\subsection{Statistical analysis}

A first ANOVA verified that the average level of alcohol was equivalent for the three driving tests. Then, four alcohol-level ANOVAs within-subjects factors were performed for each quantitative driving variable. In case of a significant effect of alcohol, Dunnett's post-hoc tests were applied, where necessary rounded out with an analysis of linear contrasts and linear regression.

For the vehicle stopped at the end of the highway circuit and for urban scenarios, the descriptive parameters of overall driver behavior were classified into obstacle avoidance (by changing lateral position and/or braking) or crash. Non-parametric Friedman ANOVAs were then performed on the number of crashes (highway and urban scenarios) and on the number of off-lane incidents (highway scenario). In case of a significant effect of alcohol, contrasts were explored with the Wilcoxon test.

The level of significance for all analyses was set at 0.05 .

\section{Results}

\subsection{Blood alcohol concentrations}

No detectable BACs were observed under the placebo condition; the mean BACs obtained prior and following the simulated tasks are summarized in table 1. 
The mean alcohol level obtained did not differ significantly between driving scenarios $\left(\mathrm{F}_{(2,30)}\right.$ $=2.03$, NS) (Fig. 2).

Insert Table 1 and Fig.2 around here

\subsection{Highway scenario}

Average performance scores and $\mathrm{p}$ values for all driving parameters analyzed are displayed in Table 2. LP values did not significantly vary as a function of BACs; the subjects always drove in the middle of the right lane, but as expected SDLP varied according to alcohol level. Post hoc analysis showed that only the highest alcohol level $(0.8 \mathrm{~g} / \mathrm{l})$ involved SDLPs significantly higher than placebo $(\mathrm{p}<0.003)$.

Insert Table 2 around here

SP and SDSP increased dose-dependently, but this effect did not reach significance. However, Dunnett's post hoc test applied to the data showed a significant increase in these two variables with $0.8 \mathrm{~g} / 1$ relative to placebo (respectively, $\mathrm{p}<0.042$ and $\mathrm{p}<0.043$ ). Finally, the number of off-lane incidents per BAC increased but did not reach significance; these incidents always occurred on road shoulders (right side of the lane). The Wilcoxon post hoc test, however, showed an increase in off-lane incidents with $0.3(\mathrm{p}<0.08)$ and $0.8 \mathrm{~g} / 1(\mathrm{p}<0.09)$ relative to placebo.

At the end of the circuit, participants were confronted with a vehicle stopped in their lane and 28 crashes were noted out of a total of 64 events. Crashes were regularly distributed between the different alcohol levels and were frequently linked only to braking. Conversely, participants who avoided collision (36 cases) combined braking and a left maneuver or made 
a left maneuver without braking. Mean response times to this unexpected obstacle did not significantly vary with the alcohol level (Table 2).

\subsection{Car following scenario}

Performance scores and $\mathrm{p}$ value are presented Table 3.

There was an overall effect of alcohol on SDLP. The highest alcohol dose $(0.8 \mathrm{~g} / \mathrm{l})$ brought about highest SDLP $(\mathrm{p}<0.001)$. IVT did not vary significantly as a function of BACs.

Insert Table 3 around here

The number of speed adjustments during the lead vehicle's stable speed period revealed a variation according to the BAC. Participants with $0.3 \mathrm{~g} / 1$ and $0.8 \mathrm{~g} / 1$ of BAC produced more adjustments than with placebo (respectively $\mathrm{p}<0.017$ and $\mathrm{p}=0.025$ ).

Mean response times to the acceleration/deceleration of the followed vehicle were faster when the followed vehicle decelerated than when it accelerated (respectively $1.99 \mathrm{~s}$ and $2.45 \mathrm{~s}$ ) but did not significantly vary according to BACs (Table 3).

\subsection{Urban scenario}

A total of 19 crashes occurred and the number of crashes increased as the BAC increased, but this variation was not significant due to the low number of crashes $\left(\chi^{2}=2.29, p=0.51\right)$ (Fig. 3). Mean response times did not reveal any significant difference according to alcohol level $\left(\mathrm{F}_{(3,45)}=0.69, \mathrm{NS}\right.$; fig. 3).

Insert Fig. 3 around here 
At initiation of the scenarios, mean speeds did not significantly vary as a function of alcohol level $\left(\mathrm{F}_{(3.45)}=0.6, \mathrm{NS}\right)($ placebo $=43.7 \mathrm{~km} / \mathrm{h} ; 0.3 \mathrm{~g} / \mathrm{l}=43.8 \mathrm{~km} / \mathrm{h} ; 0.5 \mathrm{~g} / \mathrm{l}=42.7 \mathrm{~km} / \mathrm{h} ; 0.8 \mathrm{~g} / \mathrm{l}=$ $44.7 \mathrm{~km} / \mathrm{h})$.

\section{Discussion and conclusions}

The main objective of this study was to quantify the effects of BAC on different driving scenarios: a highway driving scenario (monotonous situation), a car following scenario, and an urban driving scenario with specific events inspired by real crashes. The highway scenario involved assessing automated driving performances such as SDLP and speed; the other two scenarios implied more complex driving performances and controlled processing (Michon, 1985).

We first verified that mean alcohol levels did not significantly vary among the three scenarios tested despite the decrease of BAC from the beginning to the end of each experimental session.

Looking at lateral data, the results obtained for the highway and car following scenarios were homogeneous. BACs clearly influenced SDLP: the higher the alcohol level, the more the participants had difficulties in maintaining a stable trajectory on the road. Impairment is thus clearly alcohol dose-dependent for this automated driving parameter. This result is in accordance with past results; SDLPs are in fact known to be sensitive to the effects of psychotropic drugs, alcohol and fatigue, in natural and simulated driving situations (Liu et al. 2009; Verster and Ramaekers 2009; Owens and Ramaekers 2009; Lenné 2010; Simons et al., 2012). The increase in SDLP values obtained with $0.5 \mathrm{~g} / 1$ of alcohol relative to placebo $(+2$ $\mathrm{cm})$ is relatively close to the values obtained in other studies using similar monotonous scenarios and BACs, which confirms the validity of our results (Vermeeren 2004; Kuyper et al. 2006; Veldstra et al. 2012). Otherwise, the duration of the driving task in these two 
scenarios was relatively short, so the distances traveled were also short, while SDLP is known to increase with the duration of the task, in connection with vigilance decrement (Verster and Roth 2012b). This could be why significant differences were not found between the zero alcohol level and $0.5 \mathrm{~g} / \mathrm{l}$, but the tendency toward significance showed that behavior decrement can occur relatively rapidly.

In the highway scenario, participants drove in the middle of their lane and a slight but not significant increase of off-lane incidents occurred on road shoulders with 0.3 and $0.8 \mathrm{~g} / \mathrm{l}$ of alcohol in the blood. Note that off-lane incidents always occurred to the right of the lane, which is difficult to interpret. This result is, however, in accordance with the fact that off-road occurrences can significantly increase with alcohol (Arnedt at al. 2001). The difficulty in maintaining a stable trajectory was associated with a tendency to increase one's speed as a function of $\mathrm{BAC}$, which demonstrates a decrease in inhibitory processes (Kalmen and Gustafson 1998; Fillmore et al. 2008). Reduction in speed is in fact known to provide drivers with additional time to adapt to changes in their environment and to maintain greater vehicular control. It thus seems here that drivers failed to reduce their speed to compensate for additional impairment due to alcohol. Moreover, in the car following scenario, participants' speed adjustments to the speed of the followed car tended to be more frequent with an increase in BAC and thus attested to difficulties in regulating and stabilizing their own speed. The results obtained with the highway and car following scenarios thus demonstrate an influence of alcohol on automated driving performances, e.g. lateral control (SDLP) and longitudinal control (speed) (Lenné et al. 2010; Mets et al. 2011). Contrary to these results, the car following scenario with constant acceleration and deceleration of the lead vehicle previously failed to show alcohol effects (Veldstra et al. 2011); it thus seems that it is notably in the period of stable speed by the lead vehicle that performance decrements occur. 
Speeds at the initiation of the events (urban scenario) were not affected by BACs, but it should be pointed out that the prescribed speed was lower in this scenario than in the others. In accordance with the results of past studies, response times were not altered by the alcohol dose, either in the urban scenario or in the highway scenario, when an unexpected vehicle appeared after $15 \mathrm{~min}$ of monotonous driving. Braking reaction times are generally not sensible to low doses of alcohol (Lenné et al. 2011), even when combined with sleep deprivation (Vakulin et al. 2007).

Otherwise, in the car following scenario, participants' response times were faster after deceleration than after acceleration by the followed car. This could be due to the variation of the obstacle vehicle's size: after deceleration, the obstacle's angular size increases, which entails a higher risk of crash; conversely, after acceleration it decreased, posing less of a risk for the participant (Andersen and Sauer 2007).

In the urban scenario, although $68 \%$ of the crashes were observed with 0.5 and $0.8 \mathrm{~g} / \mathrm{l}$ of BAC, this result was linked to the fact that one woman was very sensitive to the effects of alcohol (her behavior only significantly differed from the other participants' behavior for this variable and this scenario) and systematically collided in four events with 0.5 and $0.8 \mathrm{~g} / 1$ (i.e. 8 crashes out of the 19 observed). From a safety point of view, it would be interesting to know the exact percentage of drivers (male and female) who are extremely sensitive to the effects of alcohol in order to take this percentage into account in discussions of legislative changes to the legal limits adopted in the European Community.

Urban events did not demonstrate alcohol's effects on drivers' behavior (Veldstra et al. 2011). In right crossroad, vehicle pulling out from a parking space and hidden pedestrian crossing events, the obstacle vehicle became perceptible late and was relatively unexpected; conversely, in the left crossroad, opposite vehicle crossing, braking by the vehicle ahead, and vehicle overtaking and merging back events, the participants could see the obstacle vehicle 
long before the situation became risky, and they could foresee a potential crash. It thus seems that with or without the possibility to foresee the evolution of the events, the BAC level had no effect on the behaviors adopted by the participants.

Confronted with these results, the hypothesis could be put forward that the urban scenario, where more complex performances were measured, involves less impairment by alcohol intoxication than the other two scenarios. However, to neutralize learning effects during our four experimental sessions, participants were extensively trained for the difficult situations included in the urban scenario. The effect of learning the driving circuits and foreseeing the events may have resulted in improved driving performances (e.g., better crash avoidance) over the course of the four drives, in which case the effects of alcohol would have been attenuated. Urban events thus may not be regarded as completely unexpected, probably increasing the participants' alertness which in turn could have improved their driving performance (Meskali et al. 2009). Thus, they were probably unable to induce a real-life reaction unlike for the highway scenario, which has been proved to involve behaviors that are relatively similar to those of natural driving. Finally, the weak sensitivity to the urban scenario may also be linked to the complexity and variability of possible avoidance strategies when faced with one event, unlike the automated driving tasks involved in the highway and car following tasks, where behavioral strategies are limited. These questions could be resolved with a specific protocol including matched groups subjected to just one level of alcohol and thus to just one session of urban driving.

In brief, lateral and longitudinal control of the trajectory seems to be altered more than the strategies adopted when confronted with critical or stimulating events in which attentional processes are completely involved. There thus appears to be a specific decrement of performances according to the driving task, a hypothesis that has already been put forward (Huemer and Vollrath 2010), and a relatively simple task requiring automated behavior may 
be more affected by alcohol and drugs than complex tasks that require conscious, higher-level control (Ronen et al. 2010; Veldstra et al. 2012). One limit of this study, however, is that many obvious dose-response relationships failed to reach statistical significance due to the large dispersion of responses and a limited sample size, which may have reduced the detection of real differences. Some effects could have reached significance with a larger group of participants (Helland et al. 2013). It is also important to note that our findings are based on a group of young but relatively experienced subjects (more than two years with a driving license) and cannot be generalized to other populations. Our next objective is thus to replicate the alcohol experiment with larger groups of very young, novice drivers who seem more often involved in road crashes with low alcohol level than experienced drivers (Zador et al. 2000; Keall et al. 2004; Peck et al. 2008). As road crashes are generally due to a combination of several factors, it is possible that a lack of experience combined with alcohol, even at a low level, could have a cumulative effect on performances (Lenné et al. 2010).

\section{Acknowledgements}

This research was partly funded by the TREN-05-FP6TR-SO7.61320-518404-Druid project and partly funded by IFSTTAR. We would like to thank the IFSTTAR simulation team (LEPSIS: Laboratoire Exploitation, Perception, Simulateurs et Simulations), notably Isabelle Aillerie and Fabrice Vienne, for designing the displays. We would also like to thank Sylvie Hirt, Claudine Nachtergaële and Mohamed Meskali for their help and assistance for the simulator-based data collection and processing.

\section{References}

Arnedt JT, Wilde GJS, Munt PW, MasLean AW (2001) How do prolonged wakefull and alcohol compare in the decrements they produce on a simulated driving task? Accid Anal Prev 33:337-344. 
Andersen GJ, Sauer CW (2007) Optical information for car following: the driving by visual angle (DVA) model. Hum Factors 49:878-896.

Berthelon C, Perrin C, Aillerie I, Espié S (2011) Methodology to introduce scenarios of accident in driving simulators. Interest for the analysis of drivers' behavior. Proceedings of the third conference Road and Safety Simulation, Indianapolis, 14-16 septembre2011. http://onlinepubs.trb.org/onlinepubs/conferences/2011/RSS

Biecheler-Fretel MB, Peytavin JF, the SAM group, Facy F, Martineau H (2008) SAM survey on "drugs and fatal accidents": search of substances consumed and comparison between drivers involved under the influence of alcohol or cannabis. Traffic Inj Prev 9:11-21.

Bisby JA, Leitz JR, Morgan CJA, Curran HV (2009) Decreases in recollective experience following acute alcohol: a dose-response study. Psychopharmacology 208(1):67-74.

Blomberg RD, Peck RC, Moskowitz H, Burns M, Fiorentino D (2009) The Long Beach/Fort Lauderdale relative risk study. J Saf Res 40(4):285-292.

Borkenstein RF, Crowther RF, Shumate WB, Ziel WB, Zylinan R (1964) The role of the drinking driver in traffic accidents (The Grand Rapids Study). Second edition. Blutalkohol 11(Suppl.1).

Brady JE, Li G (2012) Prevalence of alcohol and other drugs in fatally injured drivers. Addiction: doi 10.1111/j.1360-0443.2012.03993.x.

Brookhuis KA (1998) How to measure driving ability under influence of alcohol and drugs, and why. Hum Psychopharmacol 13:S64-S69.

Brookhuis KA, De Waard D, Fairclough SH (2003) Criteria for driver impairment. Ergonomics 46:433-445.

Damm L, Nachtergaële C, Meskali M, Berthelon C (2011) The evaluation of traditional and early driving learning with simulated accident scenarios. Hum Factors 53(4):323-337.

Espie S, Auberlet JM (2007) ARCHISIM: a behavioral multi-actors traffic simulation model for the study of a traffic system including ITS aspects. Int J ITS Res 5(1):7-16.

Fillmore MT, Blackburn JS, Harrison LR (2008) Acute disinhibiting effects of alcohol as a factor in risky driving behaviour. Drug Alcohol Dependence 95(1-2):97-106.

Harrison ER, Fillmore MT (2005) Are bad driver more impaired by alcohol? Sober driving precision predicts impairment from alcohol in a simulated driving task. Accid Anal Prev 37:882-889.

Harrison ELR, Fillmore MT (2011) Alcohol and distraction interact to impair driving performance. Drug Alcohol Dependence 117:31-37. 
Helland A, Jenssen, GD, Lervåg LD, Westin AA, Moen T, Sakshaug K, Lydersen S, Mørland J, Slørdal L (2013) Comparison of driving simulator performance with real driving after alcohol intake: A randomised, single blind, placebo-controlled, cross-over trial. Accid Anal Prev 53:9-16.

Holloway FA (1995) Low-dose alcohol effects on human behaviour and performance. Alcohol, Drugs Driving 11:39-56.

Huemer AK, Vollrath M (2010) Alcohol-related impairment in the Lane Change Task. Accid Anal Prev 42:1983-1988.

Kalmen H, Gustafson R (1998) Alcohol and desinhibition. Eur Addiction Res 4:150-162.

Keall MD, Frith WJ, Patterson TL (2004) The influence of alcohol, age, and number of passengers on the night-time risk of driver fatal injury in New Zealand. Accid Anal Prev 36:49-62.

Koelega HS (1995) Alcohol and vigilance performance: a review. Psychopharmacology 118:233-249.

Krüger HP (1993) Effects of low alcohol dosages: a review of the literature. In: Utselmann HD, Berghaus G, Kroj G (Eds) Alcohol, drugs and traffic safety-T92: Proceeding of the $12^{\text {th }}$ International Conference on Alcohol, Drugs and Traffic Safety, Cologne, 28 september-2 october 1992. Verlag TUV Rheinland pp 763-778.

Kuypers KP, Samyn N, Ramaekers JG (2006) MDMA and alcohol effects, combined and alone, on objective and subjective measures of actual driving performance and psychomotor function. Psychopharmacology 1987(4):467-475.

Lenné MG, Dietze PM, Triggs TJ, Walmsley S, Murphy B, Redman JN (2010) The effects of cannabis and alcohol on simulated arterial driving: influences of driving experience and task demand. Accid Anal Prev 42:859-866.

Leung S, Croft RJ, Jackson ML, Howard ME, Mckenzie RJ (2012) A comparison of the effect of mobile phone use and alcohol consumption on driving simulation performance. Traffic Inj Prev, 13(6):566-574.

Leung S, Starmer G (2005) Gap acceptance and risk-taking by young and mature drivers, both sober and alcohol-intoxicated, in a simulated driving task. Accid Anal Prev 37:10561065.

Liu CC, Hosking SG, Lenné MG (2009) Predicting driver drowsiness using vehicle measures: recent insights and future challenges. J Saf Res 40:239-245.

Louwerens JM, Gloerich ABM, d Vries G, Brookhuis KA, O'Hanlon JF (1987) The relationship between drivers' blood alcohol concentration (BAC) and actual driving 
performance during high speed travel. In Noordzig PC and Roszbach R (Eds) Alcohol, drugs and traffic safety - T86. Elsevier Science Publishers B.V. pp 183-186.

Meskali M, Berthelon C, Marie S, Denise P, Bocca ML (2009) Residual effects of hypnotics drugs in aging drivers submitted to simulated scenarios of accidents: an exploratory study. Psychopharmacology 207(3):461-467.

Mets M, Kuipers E, de Senerpont Domis LM, Leenders M, Olivier B, Verster J (2011) Effects of alcohol on highway driving in the STISIM driving simulator. Hum Psychopharmacol Clin Exp 26 (6):434-439.

Michon JA (1985) A critical review of driver behaviour models: what do we know, what should we do. In: Evans, L., Schwing, R.C. (Eds.), Human behaviour and traffic safety. Plenum press, New York, pp 485-520.

Mørland J, Steentoft A, Simonsen KW, Ojanperä I, Vuori E, Magnusdottir K, Kristinsson J, Ceder G, Kronstrand R, Christophersen A (2011) Drugs related to motor vehicle crashes in northern European countries: A study of fatally injured drivers. Accid Anal Prev 43:1920-1926.

Moskowitz H, Burns MM, Williams AF (1985) Skills performance at low blood alcohol levels. J Stud Alcohol 46:482-485.

Moskowitz H, Fiorentino D (2000) A review of the literature on the effects of low doses of alcohol on driving related skills. National Highway Traffic Safety Administration, Washington, Report DOT HS 809028.

Movig KLL, Mathijssen MPM, Nagel PHA, van Egmond T, de Gier JJ, Leufkens HGM, Egberts ACG (2004) Psychoactive substance use and the risk of motor vehicle accidents. Accid Anal Prev 36:631-636.

Ogden EJD, Moskowitz H (2004) Effects of alcohol and other drugs on driver performance. Traffic Inj Prev 5:185-198.

O’Hanlon JF, Haak TW, Blauw GJ, Riemersma JBJ (1982) Diazepam impairs lateral position control in highway driving. Science 217:79-81.

O'Hanlon JF, Volkerts ER (1986) Hypnotics and actual driving performance. Acta Psychiatr Scand [Suppl] 332:95-104.

Owens K, Ramaekers JG (2009) Drugs, driving, and models to measure driving impairment, In: Verster et al. (Eds.), Drugs, driving and traffic safety. Birkhäuser Verlag AG, Basel-boston-Berlin, pp 43-58. 
Parks V, Leister C, Patat A, Troy S, Vermeeren A, Volkerts ER, Verster JC (2002) Effect of ethanol at a blood alcohol concentration of $0.4 \mathrm{~g} / 1$ on actual driving and memory. Eur Neuropsychopharmacol 12:432-433.

Peck RC, Gebers MA, Voas RB, Romano E (2008) The relationship between blood alcohol concentration (BAC), age, and crash risk. J Saf res 39:311-319.

Philip P, Sagaspe P, Moorec N, Taillard J, Charles A, Guilleminault C, Bioulac B (2005) Fatigue, sleep restriction and driving performance. Accid Anal Prev 37:473-478.

Phillips DP, Brewer KM (2011) The relationship between serious injury and blood alcohol concentration $(\mathrm{BAC})$ in fatal motor vehicle accidents: $\mathrm{BAC}=0.01 \%$ is associated with significantly more dangerous accidents than $\mathrm{BAC}=0.00 \%$. Addiction 106(9):16141622.

Ramaekers JG, O'Hanlon JF (1994) Acrivastine, terfenadine and diphenhydramine effects on driving performance as a function of dose and time after dosing. Eur J Clin Pharmacol 47:261-266.

Ronen A, Chassidima HS, Gershona P, Parmeta Y, Rabinovicha A, Bar-Hamburgerb R, Cassutoa Y, Shinara D (2010) The effect of alcohol, THC and their combination on perceived effects, willingness to drive and performance of driving and non-driving tasks. Accid Anal Prev 42:1855-1865.

Simons R, Martens M, Ramaekers J, Krul A, Klöpping-Ketelaars I, Skopp G (2012) Effects of dexamphetamine with and without alcohol on simulated driving. Psychopharmacology 222:391-399.

Skurtveit S, Abotnes B, Christophersen SA (2002) Drugged drivers in Norway with benzodiazepine detections. Forensic Sci Int 125:75-82.

Vakulin A, Baulk SD, Catcheside PG, Anderson R, van den Heuvel CJ, Banks S, McEvoy RD (2007) Effects of moderate sleep deprivation and low-dose of alcohol on driving simulator performance and perception in young men. Sleep 30(10):1327-1333.

Veldstra JL, Brookhuis KA, De Ward D, Molmans BHW, Verstraete AG, Skopp G, Jantos R (2012) Effects of alcohol (BAC 5\%o) and ecstasy (MDMA $100 \mathrm{mg}$ ) on simulated driving performance and traffic safety. Psychopharmacology 222(3):377-390.

Vermeeren A (2004) Residual Effects of Hypnotics: Epidemiology and Clinical Implications. CNS Drugs 18:297-328.

Verster JC, Ramaekers JG (2009) The on the road driving test. In: Verster et al. (Eds.), Drugs, driving and traffic safety. Birkhäuser Verlag AG, Basel-boston-Berlin, 2009, pp 8392. 
Verster JC, Wester AE, Goorden M, van Wieringen J, Olivier B, Volkerts ER (2009) Novice drivers' performance after different alcohol dosages and placebo in the dividedattention steering stimulator (DASS). Psychopharmacology 204:127-133.

Verster JC, Roth T (2011) Standard operation procedures for conducting the on-the-road driving test, and measurement of the standard deviation of lateral position (SDLP). Int J Gen Med 4:359-371.

Verster JC, Roth T (2012a) Predicting psychopharmacological drug effects on actual driving performance (SDLP) from psychometric tests measuring driving-related skills. Psychopharmacology, 220(2):293-301.

Verster JC, Roth T (2012b) Vigilance decrement during the on-the-road driving tests: the importance of time-on-task in psychopharmacological research. Accid Anal Prev. doi: 10.1016/j.aap.2012.10.005.

Vingilis E, MacDonald S (2004) Review: drugs and traffic collisions. Traffic Inj Prev 5:1-11.

Walsh M, De Gier JJ, Christopherson AS, Verstraete AG (2004) Drugs and driving. Traffic Inj Prev 5:241-253.

West R, Wilding J, French D, Kemp R, Irving A (1993) Effect of low and moderate level doses of alcohol on driving hazard perception latency and driving speed. Addiction $88: 527-532$.

Williams EJ (1949) Experimental Designs Balanced for the Estimation of Residual Effects of Treatments. Aust J Sci Res 2(3):149-168.

Zador PL, Krawchuk SA, Voas RB (2000) Relative risk of fatal crash involvement by BAC, age and gender. US Department of Transportation National Highway Safety Administration (DOT HS 809 050) April, 2000. 
List of figures

Fig. 1 Simulator used in the experiment

Fig. 2 Average BAC obtained as a function of the driving test

Fig. 3 Number of crashes and average response times as a function of alcohol level 


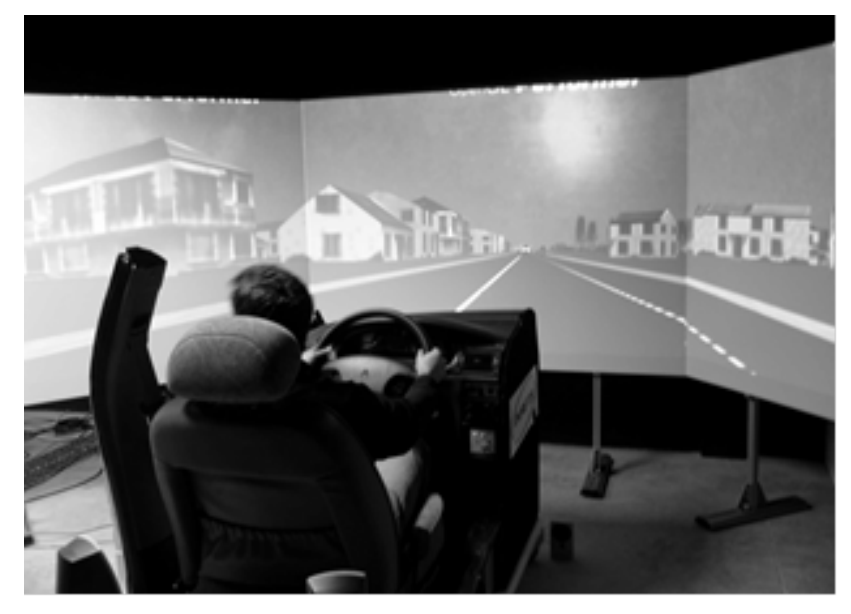

Fig. 1 


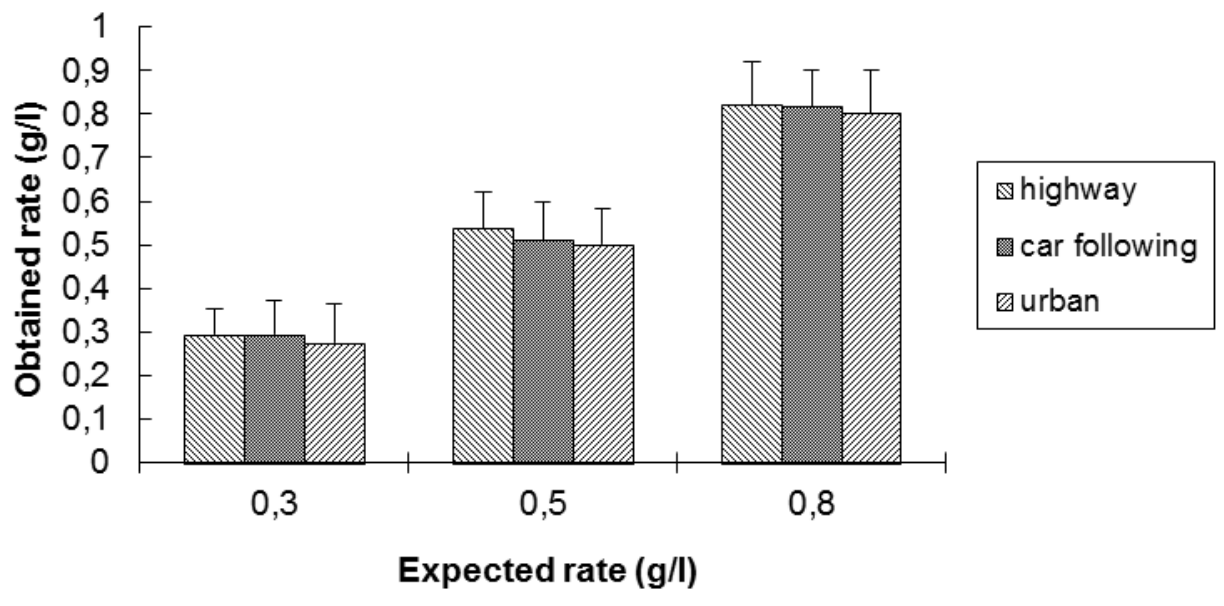

Fig.2 


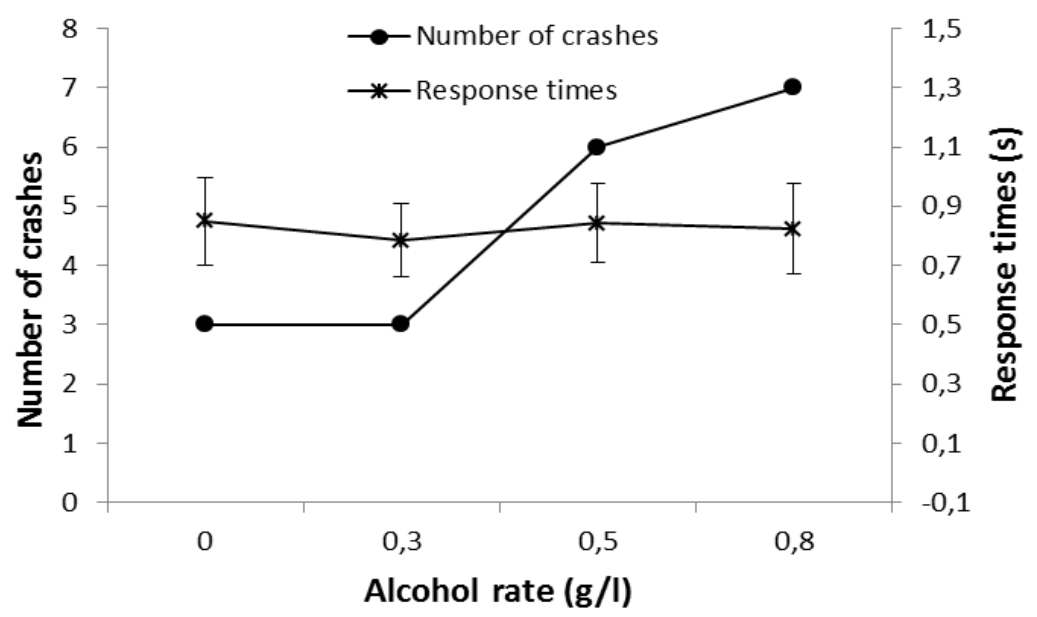

Fig. 3 
Table 1 Mean BAC level (SD) measured before and after the driving tasks

\begin{tabular}{lccc}
\hline BAC $(\mathrm{g} / \mathrm{l})$ & 0.3 & 0.5 & 0.8 \\
\hline Prior to the task & $0.033( \pm 0.07)$ & $0.055( \pm 0.06)$ & $0.83( \pm 0.07)$ \\
Following the task & $0.023( \pm 0.04)$ & $0.046( \pm 0.08)$ & $0.77( \pm 0.09)$
\end{tabular}


Table 2 Highway scenario, mean values (SD) of the driving parameters for each BAC

$\begin{array}{cccccc}\text { BAC }(\mathrm{g} / \mathrm{l}) & 0 & 0.3 & 0.5 & 0.8 & \begin{array}{c}\text { Main within-subjects } \\ \text { effect }\end{array} \\ \text { LP }(\mathrm{cm}) & 72.83 & 73.14 & 73.01 & 73.42 & \mathrm{~F}_{(3,45)}=1.34, \mathrm{n} . \mathrm{s} \\ & (20.30) & (24.08) & (18.13) & (20.89) & \\ \text { SDLP }(\mathrm{cm}) & 26.44 & 25.85 & 28.42 & 31.89 & \mathrm{~F}_{(3,45)}=5.27, \mathrm{p}<0.003 \\ & (6.75) & (7.24) & (6.83) & (8.71) & \\ \text { SP }(\mathrm{km} / \mathrm{h}) & 110.68 & 110.59 & 110.86 & 112.48 & \mathrm{~F}_{(3,45)}=2.38, \mathrm{p}=0.082 \\ & (1.79) & (2.15) & (2.91) & (4.16) & \\ \text { SDSP }(\mathrm{km} / \mathrm{h}) & 1.56 & 1.85 & 1.91 & 2.42 & \mathrm{~F}_{(3,45)}=1.65, \mathrm{n} . \mathrm{s} \\ & (1.24) & (0.99) & (1.58) & (2.31) & \\ \text { Number of } & 5 & 14 & 7 & 44 & \chi^{2}(3)=5.8, \mathrm{n} . \mathrm{s} \\ \text { off-lane incidents } & (0.47) & (1.26) & (0.89) & (5.73) & \\ \text { Number of } & 5 & 8 & 7 & 8 & \chi^{2}(3)=1.71, \mathrm{n} . \mathrm{s} \\ \text { crashes } & & & & & \\ \text { RT (s) } & 0.47 & 0.51 & 0.54 & 0.57 & \mathrm{~F}_{(3,45)}=1.60, \mathrm{n} . \mathrm{s} \\ & (0.08) & (0.11) & (0.16) & (0.16) & \end{array}$


Table 3 Car following scenario, mean values (SD) of the driving parameters for each BAC

\begin{tabular}{cccccc}
\hline BAC (g/l) & 0 & 0.3 & 0.5 & 0.8 & $\begin{array}{c}\text { Main within-subjects } \\
\text { effect }\end{array}$ \\
\hline SDLP (cm) & 18.35 & 19.21 & 19.74 & 23.30 & $\mathrm{~F}_{(3,45)}=5.77, \mathrm{p}<0.002$ \\
& $(6.65)$ & $(5.61)$ & $(6.13)$ & $(6.68)$ & \\
IVT (s) & 2.55 & 2.25 & 2.47 & 2.22 & $\mathrm{~F}_{(3,45)}=1.39, \mathrm{n} . \mathrm{s}$ \\
& $(0.89)$ & $(1.02)$ & $(1.13)$ & $(0.80)$ & \\
Number of & 44.5 & 57 & 52.44 & 56.25 & $\mathrm{~F}_{(3,45)}=2.79, \mathrm{p}<0.05$ \\
speed & $(18.23)$ & $(20.30)$ & $(22.39)$ & $(16.54)$ & \\
adjustments & & & & & \\
RT (s) & 2.42 & 1.9 & 2.23 & 2.34 & $\mathrm{~F}_{(3,45)}=1.82, \mathrm{n} . \mathrm{s}$ \\
& $(1.06)$ & $(0.68)$ & $(0.76)$ & $(1.33)$ &
\end{tabular}

